\title{
Elucidation of the Stereochemistry of Diterpene Derivatives Obtained by Palladium Catalyzed Oxidative Coupling-Oxidation of Camphene
}

\author{
Elena V. Gusevskaya* and Marcio J. da Silva \\ Departamento de Química, ICEx, Universidade Federal de Minas Gerais, CP 702, 31270-901 \\ Belo Horizonte - MG, Brazil
}

\begin{abstract}
As estruturas dos derivados diterpénicos resultantes do acoplamento oxidativo - oxidação do canfeno catalisados por paládio, ou seja, bis(2,2-dimetil-biciclo[2.2.1]hepto-3-ilideno)etano e (4,4dimetilbiciclo[3.2.1]octo-2-on-3-il)(2,2-dimetilbiciclo[2.2.1]hepto-3-ilideno)metano, foram estudadas utilizando-se as técnicas de $\mathrm{RMN}$ de ${ }^{1} \mathrm{H}$ e de ${ }^{13} \mathrm{C}$ uni e bidimensionais. Sua estereoquímica foi determinada utilizando-se NOESY.
\end{abstract}

The structures of diterpene derivatives resulting from the palladium catalyzed tandem oxidative coupling-oxidation of camphene, i.e., bis(2,2-dimethyl-bicyclo[2.2.1]hept-3-ylidene)ethane and (4,4dimethylbicyclo[3.2.1] oct-2-on-3-yl)(2,2-dimethylbicyclo[2.2.1]hept-3-ylidene)methane, were elucidated using one- and two-dimensional ${ }^{1} \mathrm{H}$ and ${ }^{13} \mathrm{C}$ NMR techniques. Their stereochemistry was determined unambiguously by NOESY experiments.

Keywords: camphene oxidation, palladium catalyst, diterpene derivatives, NMR spectroscopy, NOESY

\section{Introduction}

Functionalization of inexpensive naturally occurring monoterpenes using transition metal homogeneous catalysis can provide various derivatives of interest to perfumery, flavor and pharmaceutical industries as well as useful synthetic intermediates and chiral building blocks. ${ }^{1,2}$ We have recently reported that allylic acetates, alcohols, aldehydes and esters can be obtained in good yields and in some cases with high stereoselectivity by catalytic oxidation or carbonylation of some monoterpenes, such as limonene, $\beta$-pinene, and camphene. ${ }^{3}$

The reactions of olefin oxidation by palladium salts may be incorporated into catalytic processes by use of reversible reoxidants, such as $\mathrm{CuCl}_{2}$ (the Wacker type catalyst). Although these processes have been developed into commercially important methods for the oxidation of olefins by dioxygen, the most abundant and cheapest oxidant, their applications to natural product synthesis are rather scarce. We previously reported a selective $\mathrm{PdCl}_{2} /$ $\mathrm{CuCl}_{2}$ catalyzed oxidation of limonene, however in the case of bicyclic monoterpenes, such as $\beta$-pinene and camphene, $\mathrm{CuCl}_{2}$ promoted the extensive skeletal rearrangements of the substrates. ${ }^{3}$ Then, we developed a

* e-mail: elena@dedalus.lcc.ufmg.br
$\mathrm{CuCl}_{2}$-free system for selective oxidation of $\beta$-pinene and camphene into allylic and glycol derivatives, respectively, using $\mathrm{H}_{2} \mathrm{O}_{2}$ as the final oxidant and $\mathrm{Pd}(\mathrm{OAc})_{2}$ as catalyst. ${ }^{3}$

In a further study, we applied a $\mathrm{Pd}(\mathrm{II}) / \mathrm{NO}_{3}^{-}$catalytic system, a valuable alternative to the Wacker catalyst, ${ }^{4}$ to the oxidation of camphene (1) by dioxygen. We found a new process consisting in oxidative coupling of camphene $\left(\mathrm{C}_{10}\right)$ giving diene $\mathbf{2}\left(\mathrm{C}_{20}\right)$ and its further oxidation to $\beta, \gamma$ unsaturated ketone $\mathbf{3}\left(\mathrm{C}_{20}\right)$ (Figure 1).

In order to fully characterize compounds $\mathbf{2}$ and $\mathbf{3}$, we used one- and two-dimensional ${ }^{1} \mathrm{H}$ and ${ }^{13} \mathrm{C}$ NMR techniques as well as gas chromatography-mass spectroscopy (GC-MS) and IR spectroscopy. In this paper, we report the results of the elucidation of the stereochemistry of these diterpene derivatives, mainly by nuclear Overhauser enhancement spectroscopy (NOESY).

\section{Experimental}

\section{General}

Infrared spectra were recorded on a Mattson FTIR 3000/ Galaxy Series spectrometer. Mass spectra were obtained by GC-MS on a Hewlett-Packard MSD 5890/Series II instrument operating at $70 \mathrm{eV}$ equipped with a HP Ultra 1 capillary column. The uncorrected melting point was 


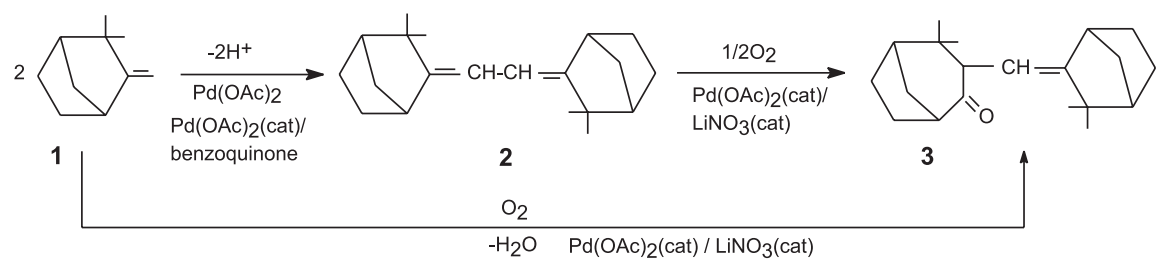

Figure 1. Synthesis of bis(2,2-dimethyl-bicyclo[2.2.1]hept-3-ylidene)ethane (2) and (4,4-dimethylbicyclo[3.2.1]oct-2-on-3-yl)(2,2dimethylbicyclo[2.2.1] hept-3-ylidene)methane (3) by the palladium catalyzed tandem oxidative coupling-oxidation of camphene (1).

determined on a Mettler FP82HT melting point apparatus. ${ }^{1} \mathrm{H}$ and ${ }^{13} \mathrm{C}$ NMR spectra were obtained using a Bruker DRX-400 AVANCE spectrometer with a magnetic field induction of $9.4 \mathrm{~T}$. in $\mathrm{CDCl}_{3}$ solutions (concentration of $30 \mathrm{mg} \mathrm{mL}^{-1}$ ). Analyses were performed at $298 \mathrm{~K}$. Chemical shifts are referenced to tetramethylsilane as internal standard. Standard Bruker pulse sequences (given in parentheses) were used for NMR experiences and experimental conditions were as follows. For ${ }^{1} \mathrm{H}$ NMR spectra (zg30): dwell time (DW) $146.400 \mu \mathrm{s}$, acquisition time (AQ) $4.131 \mathrm{~s}$, number of transients (NS) 16, recycle delay (D1) $1.000 \mathrm{~s}$. For ${ }^{13} \mathrm{C}$ NMR spectra (zgpg30): DW $31.400 \mu \mathrm{s}$, AQ $2.058 \mathrm{~s}$, NS 1024, D1 $2.000 \mathrm{~s}$, decoupling multiple resonance method Waltz-16. For DEPT 135 (dept135): DW $15.700 \mu \mathrm{s}$, AQ $1.029 \mathrm{~s}, \mathrm{NS} 512$, D1 $2.000 \mathrm{~s}$. For g-COSY (cosy45): DW $227.200 \mu \mathrm{s}, \mathrm{AQ} 0.233 \mathrm{~s}$, NS 8, D1 $2.000 \mathrm{~s}$, data points (TD) $1024\left(\mathrm{~F}_{2}\right)$ and $256\left(\mathrm{~F}_{1}\right)$. For HMQC (inv4tp): DW $249.600 \mu \mathrm{s}, \mathrm{AQ} 0.233 \mathrm{~s}$, NS 8, D1 $2.000 \mathrm{~s}$, TD $1024\left(\mathrm{~F}_{2}\right)$ and $512\left(\mathrm{~F}_{1}\right)$. For HMBC (inv4lplrnd): DW $62.400 \mu \mathrm{s}$, AQ $0.256 \mathrm{~s}$, NS 16, D1 $2.000 \mathrm{~s}$, TD $2048\left(\mathrm{~F}_{2}\right)$ and $1024\left(\mathrm{~F}_{1}\right)$, delay for long-range coupling (D6) $0.07 \mathrm{~s}$. For 2D NOESY (noesytp): DW $222.400 \mathrm{~ms}$, AQ 0.446 s, NS 32, D1 $2.000 \mathrm{~s}$, mixing time $550 \mathrm{~ms}$, time evolution $6.50 \mu \mathrm{s}$, TD $2048\left(\mathrm{~F}_{2}\right)$ and $512\left(\mathrm{~F}_{1}\right)$.

The data were processed before Fourier transformation as follows. For ${ }^{1} \mathrm{H}$ NMR spectra: using Gaussian multiplication (line broadening $-0.3 \mathrm{~Hz}$, Gaussian broadening 0.2). For ${ }^{13} \mathrm{C}$ NMR spectra: using exponential multiplication (line broadening 1.0 Hz). For DEPT 135: using exponential multiplication (line broadening $1.0 \mathrm{~Hz}$ ). For g-COSY: using a sine-bell function in both dimensions. For HMQC: using a sine-bell function in the $\mathrm{F}_{1}$ dimension and a sine-bell squared window function in the $F_{2}$ dimension. For HMBC: using a sine-bell squared window function in both dimensions. For 2D NOESY: using a sinebell function in both dimensions.

\section{Oxidation of camphene: general procedure}

Reactions were carried out in a stirred glass reactor connected to a gas burette to monitor a dioxygen uptake and followed by GC using a Shimadzu 14B instrument fitted with a Carbowax $20 \mathrm{M}$ capillary column and a flame ionization detector. The typical run conditions for the synthesis of compound 2 were as follows: $\mathrm{Pd}(\mathrm{OAc})(0.1$ $\mathrm{mmol})$, benzoquinone $(0.5 \mathrm{mmol})$, camphene $(5 \mathrm{mmol})$, acetic acid $(10 \mathrm{~mL}), 60^{\circ} \mathrm{C}, 1$ bar of dioxygen, $6 \mathrm{~h}$. Diene 2 was formed in stoichiometric amounts based on benzoquinone ( $96 \%$ selectivity at $22 \%$ conversion, which corresponded to a $21 \%$ GC yield, isolated yield was $14 \%$ ). The typical run conditions for the synthesis of compound 3 were as follows: $\mathrm{Pd}(\mathrm{OAc})(0.1 \mathrm{mmol}), \mathrm{LiNO}_{3}(1.8 \mathrm{mmol})$, camphene $(5 \mathrm{mmol})$, acetic acid $(5 \mathrm{ml}), 60^{\circ} \mathrm{C}, 1 \mathrm{bar}$ of dioxygen, 8.5 h. Enone 3 was formed with a $92 \%$ selectivity at $80 \%$ conversion of camphene ( $74 \%$ GC yield, $51 \%$ isolated yield). Compounds $\mathbf{2}$ and $\mathbf{3}$ were isolated from the reaction solutions as isomeric mixtures $\mathbf{2} \mathbf{a} / \mathbf{2} \mathbf{b}$ (ca. 40/60) and 3a/3b (60/40-30/70) by column chromatography (silica) using mixtures of hexane, $\mathrm{CH}_{2} \mathrm{Cl}_{2}$ and methanol as eluents.

Bis(2,2-dimethyl-bicyclo[2.2.1]hept-3-ylidene)ethane (2a/2b). White solid, mp $182-184{ }^{\circ} \mathrm{C}\left(\mathrm{Lit}^{5} 183-184{ }^{\circ} \mathrm{C}\right)$; IR $(\mathrm{KBr}) v_{\max } / \mathrm{cm}^{-1}: 3020[\mathrm{n}(=\mathrm{C}-\mathrm{H})], 2950,2875,1625[\mathrm{n}$ $(\mathrm{C}=\mathrm{C})], 1460,1375,1360,1250,1120,890,870,810[\delta$ (=C-H)]; MS $\mathrm{m} / \mathrm{z}$ (rel. int.): $\mathbf{2 a}$ (shorter GC retention time): $270\left(\mathrm{M}^{+}, 70\right), 255$ [( $\left.\left(\mathrm{M}^{-\mathrm{CH}_{3}}\right)^{+}, 100\right], 227$ (27), 202 (20), 161 (27), 133 (44), 121 (30), 119 (73), 117 (30), 109 (44), 107 (58), 105 (71), 95 (73), 93 (71), 91 (89), 81 (58), 79 (67), 77 (53), 69 (56), 67 (95), 55 (58); 2b: $270\left(\mathrm{M}^{+}, 79\right), 255$ [(M$\left.\left.\mathrm{CH}_{3}\right)^{+}, 100\right], 227$ (30), 202 (19), 161 (19), 133 (41), 121 (25), 119 (62), 117 (30), 109 (36), 107 (50), 105 (65), 95 (69), 93 (62), 91 (71), 81 (52), 79 (57), 77 (50), 69 (51), 67 (95), 55 (56); Anal._Calcd. for $\mathrm{C}_{20} \mathrm{H}_{30}$ : C, 88.82; H, 11.18 . Found: $\mathrm{C}, 88.36 ; \mathrm{H}, 11.12$. For ${ }^{1} \mathrm{H}$ and ${ }^{13} \mathrm{C}$ NMR data see Table 1.

(4,4-Dimethylbicyclo[3.2.1]oct-2-on-3-yl)(2,2dimethylbicyclo[2.2.1]hept-3-ylidene)methane (3a/3b). Light yellow oil, IR (film) $v_{\max } / \mathrm{cm}^{-1}: 3025$ [n $\left.(=\mathrm{C}-\mathrm{H})\right], 2975$, 2875, 1700 [n (C=O)], 1630 [n (C=C)], 1465, 1380, 1365, 1250, 1090, 1025, 800 [ $\delta(=\mathrm{C}-\mathrm{H})]$; MS $m / z$ (rel. int.): $\mathbf{3 a}$ (exo, shorter GC retention time): $286\left(\mathrm{M}^{+}, 70\right), 271$ [(M$\left.\left.\mathrm{CH}_{3}\right)^{+}, 35\right], 202$ (46), 175 (51), 133 (35), 119 (44), 109 
(95), 108 (44), 107 (67), 105 (49), 95 (44), 93 (58), 91 (67), 81 (84), 79 (50), 69 (50), 67 (100), 55 (79), 43 (38), 41 (97); 3b (endo): $286\left(\mathrm{M}^{+}, 100\right), 271\left[\left(\mathrm{M}^{-} \mathrm{CH}_{3}\right)^{+}, 44\right], 217$ (35), 202 (60), 175 (67), 133 (44), 119 (46), 117 (40), 109 (98), 108 (46), 107 (70), 105 (56), 95 (44), 93 (58), 91 (67), 81 (86), 79 (53), 69 (51), 67 (98), 55 (73), 43 (35), 41 (86); Anal._Calcd. for $\mathrm{C}_{20} \mathrm{H}_{30} \mathrm{O}: \mathrm{C}, 83.92 ; \mathrm{H}, 10.49$. Found: C, 83.50; H, 10.38. For ${ }^{1} \mathrm{H}$ and ${ }^{13} \mathrm{C}$ NMR data see Table 2.

\section{Results and Discussion}

The application of the $\mathrm{Pd}(\mathrm{II}) / \mathrm{NO}_{3}^{-}$catalytic system to the oxidation of camphene (1) by dioxygen resulted in oxidative coupling of camphene $\left(\mathrm{C}_{10}\right)$ giving diene $\mathbf{2}\left(\mathrm{C}_{20}\right)$ and its further oxidation to $\beta, \gamma$-unsaturated ketone $\mathbf{3}\left(\mathrm{C}_{20}\right)$ (Figure 1).

Reactions were carried out in acetic acid solutions at $60{ }^{\circ} \mathrm{C}$ and 1 bar of dioxygen with catalytic amounts of $\mathrm{Pd}(\mathrm{OAc})_{2}$ and $\mathrm{LiNO}_{3}$. Under these conditions, camphene was converted in a $74 \%$ chromatographic yield to product 3 (80\% conversion, $92 \%$ selectivity). It has been shown that the reaction proceeds via the intermediate formation of compound 2, which can be obtained, in the absence of $\mathrm{LiNO}_{3}$, as the only product in stoichiometric amounts based on palladium. Oxidative coupling of $\mathbf{1}$ into diene $\mathbf{2}$ was also realized using catalytic amounts of $\mathrm{Pd}(\mathrm{OAc})_{2}$ and benzoquinone as reoxidant under similar conditions. The primarily formed $\mathbf{2}$ can be rapidly and selectively converted into 3 by the addition of $\mathrm{LiNO}_{3}$ to the reaction solutions containing Pd(II) ions. This clearly shows the consecutive character of the reactions. Compounds $\mathbf{2}$ and $\mathbf{3}$ were isolated from the reaction solutions as isomeric mixtures $\mathbf{2 a} / \mathbf{2} \mathbf{b}$ and $\mathbf{3 a} \mathbf{a} \mathbf{3 b}$.

The chemical nature of new compounds resulting from the oxidation of camphene has been firstly elucidated by GC-MS and IR and then by NMR spectroscopy. Mass spectra of $\mathbf{2 a}$ and $\mathbf{2 b}$ show the same molecular ion peak of 270 mass units and are very similar, indicating that these compounds seem to be closely related isomers. The observed molecular weight corresponds to the products of the dimerization of camphene with the abstraction of two hydrogen atoms, i.e., oxidative coupling. The IR spectrum of mixture $\mathbf{2 a} / \mathbf{2} \mathbf{b}$ exhibits absorptions due to $\mathrm{C}=\mathrm{CH}$ fragments: at $3020[v(=\mathrm{C}-\mathrm{H})], 1625[v(\mathrm{C}=\mathrm{C})]$ and $810 \mathrm{~cm}^{-1}$ $[\delta(=\mathrm{C}-\mathrm{H})]{ }^{6,7}$ Mass spectra of $\mathbf{3 a}$ and $\mathbf{3 b}$ are also very similar. The molecular ions observed give molecular weights of 286 corresponding to the products of the addition of one oxygen atom to compound $\mathbf{2}$. The IR spectrum of mixture 3a/3b shows a strong absorption at $1700 \mathrm{~cm}^{-1}$, which can be assigned to the stretching vibration of the carbonyl group, and adsorptions due to the $\mathrm{C}=\mathrm{CH}$ fragment: at 3025
$[\nu(=\mathrm{C}-\mathrm{H})], 1630[\nu(\mathrm{C}=\mathrm{C})]$ and $800 \mathrm{~cm}^{-1}[\delta(=\mathrm{C}-\mathrm{H})] \cdot{ }^{6,7}$ Based on the analysis of GC-MS, IR, ${ }^{1} \mathrm{H}$ and ${ }^{13} \mathrm{C}-\mathrm{NMR}$ spectroscopy data we suggested structures $\mathbf{2}$ and $\mathbf{3}$ for the products (Figures 2 and 3). The assignment of hydrogen and carbon resonances (Tables 1 and 2) was helped by $\operatorname{COSY}\left({ }^{1} \mathrm{H},{ }^{1} \mathrm{H}\right), \mathrm{HMQC}\left({ }^{1} \mathrm{H},{ }^{13} \mathrm{C}\right), \mathrm{HMBC}\left({ }^{1} \mathrm{H},{ }^{13} \mathrm{C}\right)$ and DEPT NMR experiments. The study of the HMBC spectra of $\mathbf{3}$ has delivered decisive arguments for building its molecular skeleton. The oxidative ring expansion of one of the isocamphane (bicycloheptane) fragment of $\mathbf{2}$ to a bicyclooctane one has been unambiguously proved by the analysis of long-range cross signals in HMBC spectra (Table 2). Carbonyl carbon C-3 correlates with both $\mathrm{H}-7 \mathrm{a}$ and $\mathrm{H}-8$, while olefinic carbon $\mathrm{C}-3$ ' correlates with $\mathrm{H}-8$ via ${ }^{3} J_{\mathrm{CH}}$. Thus, compound $\mathbf{3}$ has a structure of $\beta, \gamma$-unsaturated ketone with the carbonyl group being endo cyclic. The $9.6 \mathrm{~Hz}$ vicinal coupling between $\mathrm{H}-8^{\prime}$ and $\mathrm{H}-8$, which show a strong correlation signal in COSY spectra, the multiplicity of the H-8 signal (doublet) and no vicinal coupling between H-8 and H-4, expected for isocamphane systems, ${ }^{6}$ provide additional evidences for the ring expansion and the $\mathrm{C}=\mathrm{O}$ incorporation between C-4 and C-8. Formally, the formation of this new skeleton from diene 2 can be rationalized as the cleavage of the $\mathrm{C}-2-\mathrm{C}-3$ bond and the formation of a new C-2-C-8 bond. To facilitate the discussion and signal comparison, carbon numbering used for $\mathbf{2}$ is maintained for $\mathbf{3}$.
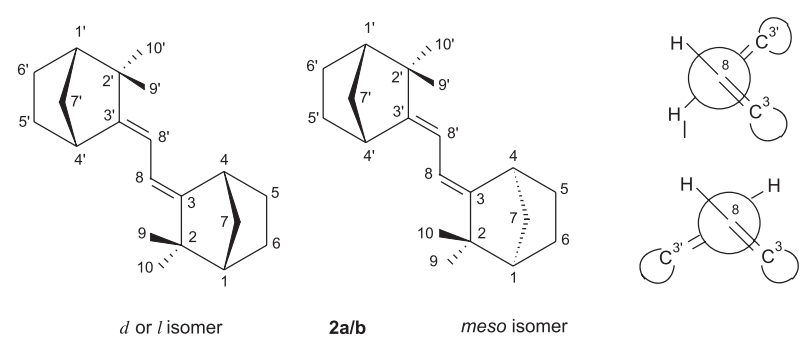

$d$ or $l$ isomer

$2 a / b$

meso isomer

Figure 2. Structure and numbering of $(E, E)$ bis(2,2-dimethylbicyclo[2.2.1] hept-3-ylidene)ethane (2). Newman projections for two possible skew conformations of 2 (C-8 - C-8' view).

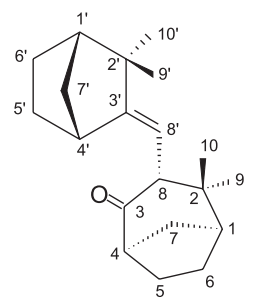

3a $(E)$-exo

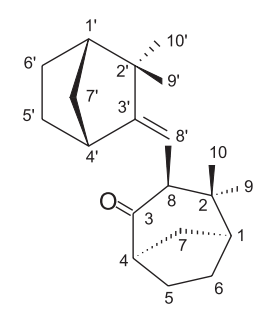

3b (E)-endo
Figure 3. Structure and numbering of (4,4-dimethylbicyclo [3.2.1] oct-2-on-3-y1)(2,2-dimethylbicyclo[2.2.1] hept-3ylidene)methane (3). (Carbon numbering used for compound $\mathbf{2}$ is maintained for $\mathbf{3}$ to facilitate a discussion.) 
Table 1. Chemical shifts $(\delta, \mathrm{ppm})$ and coupling constants $(J, \mathrm{~Hz}$, in parentheses) for compounds $\mathbf{2 a}$ and $\mathbf{2 b}$

\begin{tabular}{|c|c|c|c|c|}
\hline \multirow[t]{2}{*}{ Atom $^{a}$} & \multicolumn{2}{|c|}{$2 \mathbf{a}$} & \multicolumn{2}{|c|}{$2 \mathbf{b}$} \\
\hline & $\delta\left({ }^{1} \mathrm{H}\right)^{\mathrm{b}}$ & $\delta\left({ }^{13} \mathrm{C}\right)$ & $\delta\left({ }^{1} \mathrm{H}\right)^{\mathrm{b}}$ & $\delta\left({ }^{13} \mathrm{C}\right)$ \\
\hline $1,1^{\prime}$ & 1.89 (bd, 2.2, H-6eq, H-6'eq) & 48.10 & 1.89 (bd, 2.2, H-6eq, H-6'eq) & 48.10 \\
\hline $2,2^{\prime}$ & & 42.42 & & 42.36 \\
\hline $3,3^{\prime}$ & & 155.44 & & 155.44 \\
\hline $4,4^{\prime}$ & 3.09 (bd, 4.8, H-7b, H-7'b) & 41.51 & 3.08 (bd, 4.8, H-7b, H-7'b) & 41.51 \\
\hline $5 a x, 5 ' a x$ & $1.18-1.25(\mathrm{~m})$ & 28.20 & $1.18-1.25(\mathrm{~m})$ & 28.09 \\
\hline $5 \mathrm{eq}, 5$ 'eq & $1.61-1.65(\mathrm{~m})$ & & $1.61-1.65(\mathrm{~m})$ & \\
\hline $6 a x, 6 ' a x$ & $1.65-1.68(\mathrm{~m})$ & 23.92 & $1.65-1.68(\mathrm{~m})$ & 23.90 \\
\hline $6 \mathrm{eq}, 6 \mathrm{eq}^{\prime}$ & $1.35-1.43(\mathrm{~m})$ & & $1.35-1.43(\mathrm{~m})$ & \\
\hline $7 \mathrm{a}, 7$ 'a & $1.22\left(\mathrm{~d}, 9.3, \mathrm{H}-7 \mathrm{~b}, \mathrm{H}-7^{\prime} \mathrm{b}\right)$ & 37.49 & $1.22\left(\mathrm{~d}, 9.3, \mathrm{H}-7 \mathrm{~b}, \mathrm{H}-7^{\prime} \mathrm{b}\right)$ & 37.40 \\
\hline $7 \mathrm{~b}, 7^{\prime} \mathrm{b}$ & $1.68-1.71(\mathrm{~m})$ & & $1.68-1.71(\mathrm{~m})$ & \\
\hline $8,8^{\prime}$ & $5.73(\mathrm{~s})$ & 113.30 & $5.71(\mathrm{~s})$ & 113.22 \\
\hline $9,9^{\prime}$ & $1.06(\mathrm{~s})$ & 29.31 & $1.05(\mathrm{~s})$ & 29.29 \\
\hline $10,10^{\prime}$ & $1.02(\mathrm{~s})$ & 26.05 & $1.03(\mathrm{~s})$ & 26.00 \\
\hline
\end{tabular}

${ }^{a}$ Usual numbering for terpenes.

${ }^{\mathrm{b}}$ Resonance multiplicities, coupling constants and coupled partners in parentheses: (s) singlet, (d) doublet), (t) triplet, (m) multiplet, (b) broad.

Table 2. Chemical shifts $(\delta$, ppm), coupling constants $(J, \mathrm{~Hz}$, in parenthesis) and HMBC correlations for compounds $\mathbf{3 a}$ and $\mathbf{3 b}$

\begin{tabular}{|c|c|c|c|c|c|c|}
\hline \multirow[t]{2}{*}{ Atom $^{\mathrm{a}}$} & \multicolumn{3}{|c|}{$3 \mathbf{a}$} & \multicolumn{3}{|c|}{$\mathbf{3 b}$} \\
\hline & $\delta\left({ }^{1} \mathrm{H}\right)^{\mathrm{b}}$ & $\delta\left({ }^{13} \mathrm{C}\right)$ & НМВС & $\delta\left({ }^{1} \mathrm{H}\right)^{\mathrm{b}}$ & $\delta\left({ }^{13} \mathrm{C}\right)$ & HMBC \\
\hline 1 & 1.93 (bd, 4.0, H-6eq) & 47.48 & H-9, H-10 & 1.93 (bd, 4.0, H-6eq) & 47.18 & H-9, H-10 \\
\hline 2 & & 43.48 & $\mathrm{H}-8, \mathrm{H}-9, \mathrm{H}-10$ & & 43.07 & $\mathrm{H}-8, \mathrm{H}-9, \mathrm{H}-10$ \\
\hline 3 & & 214.73 & H-8, H-7a & & 214.68 & H-8, H-7a \\
\hline 4 & $2.69(\mathrm{~s}, \mathrm{~b})$ & 50.80 & H-7a & $2.69(\mathrm{~s}, \mathrm{~b})$ & 50.80 & H-7a \\
\hline $5 \mathrm{ax}$ & $1.23-1.29(\mathrm{~m})$ & 27.43 & $\mathrm{H}-1, \mathrm{H}-7 \mathrm{~b}$ & $1.23-1.29(\mathrm{~m})$ & 27.50 & $\mathrm{H}-1, \mathrm{H}-7 \mathrm{~b}$ \\
\hline 5 eq & $1.70-1.85(\mathrm{~m})$ & & & $1.70-1.85(\mathrm{~m})$ & & \\
\hline $6 a x$ & $2.03-2.07(\mathrm{~m})$ & 24.94 & $\mathrm{H}-4, \mathrm{H}-7 \mathrm{~b}$ & $2.03-2.07(\mathrm{~m})$ & 24.91 & $\mathrm{H}-4, \mathrm{H}-7 \mathrm{~b}$ \\
\hline $6 \mathrm{eq}$ & $1.70-1.85(\mathrm{~m})$ & & & $1.70-1.85(\mathrm{~m})$ & & \\
\hline $7 \mathrm{a}$ & $1.61-1.71(\mathrm{~m})$ & 35.16 & H-6 & $1.61-1.71(\mathrm{~m})$ & 35.00 & H-6 \\
\hline $7 b$ & $2.11(\mathrm{~d}, 12.0, \mathrm{H}-7 \mathrm{~b})$ & & & $2.11(\mathrm{~d}, 12.0, \mathrm{H}-7 \mathrm{~b})$ & & \\
\hline 8 & $2.99\left(\mathrm{~d}, 9.6, \mathrm{H}-8^{\prime}\right)$ & 53.81 & H-9, H-10 & $2.95\left(\mathrm{~d}, 9.6, \mathrm{H}-8^{\prime}\right)$ & 53.38 & H-9, H-10 \\
\hline 9 & $0.84(\mathrm{~s})$ & 23.13 & $\mathrm{H}-8, \mathrm{H}-10$ & $0.95(\mathrm{~s})$ & 26.15 & $\mathrm{H}-8, \mathrm{H}-10$ \\
\hline 10 & $0.96(\mathrm{~s})$ & 27.33 & $\mathrm{H}-8, \mathrm{H}-9$ & $0.80(\mathrm{~s})$ & 22.85 & $\mathrm{H}-8, \mathrm{H}-9$ \\
\hline $1^{\prime}$ & 1.89 (bd, 2.4, H-6'eq) & 47.89 & H-9', H-10' & 1.89 (bd, 2.4, H-6'eq) & 47.81 & H-9', H-10' \\
\hline $2^{\prime}$ & & 42.08 & H-7'a, H-8', H-9', H-10' & & 42.00 & H-7'a, H-8', H-9', H-10' \\
\hline $3^{\prime}$ & & 158.87 & H-8, H-7'a, H-9', H-10' & & 158.81 & H-8, H-7'a, H-9', H-10' \\
\hline $4^{\prime}$ & $2.70(\mathrm{bd}, 4.4, \mathrm{H}-7$ 'b) & 41.35 & H- $8^{\prime}$ & 2.76 (bd, 4.4, H-7'b) & 41.39 & H- $8^{\prime}$ \\
\hline $5^{\prime} \mathrm{ax}$ & $1.23-1.29(\mathrm{~m})$ & 27.54 & $\mathrm{H}-1^{\prime}, \mathrm{H}-7^{\prime} \mathrm{b}$ & $1.23-1.29(\mathrm{~m})$ & 27.87 & $\mathrm{H}-1^{\prime}, \mathrm{H}-\mathrm{7}^{\prime} \mathrm{b}$ \\
\hline $5^{\prime}$ eq & $1.70-1.85(\mathrm{~m})$ & & & $1.70-1.85(\mathrm{~m})$ & & \\
\hline 6 'ax & $1.70-1.85(\mathrm{~m})$ & 23.87 & & $1.70-1.85(\mathrm{~m})$ & 23.84 & \\
\hline $6^{\prime} \mathrm{eq}$ & $1.34-1.40(\mathrm{~m})$ & & & $1.34-1.40(\mathrm{~m})$ & & \\
\hline $7 ' \mathrm{a}$ & $1.20\left(\mathrm{~d}, 9.6, \mathrm{H}-7^{\prime} \mathrm{b}\right)$ & 37.80 & & $1.20\left(\mathrm{~d}, 9.6, \mathrm{H}-7^{\prime} \mathrm{b}\right)$ & 37.20 & \\
\hline 7 'b & $1.58-1.67(\mathrm{~m})$ & & & $1.58-1.67(\mathrm{~m})$ & & \\
\hline $8^{\prime}$ & $4.97(\mathrm{~d}, 9.6, \mathrm{H}-8)$ & 109.25 & $\mathrm{H}-8$ & $4.97(\mathrm{~d}, 9.6, \mathrm{H}-8)$ & 109.00 & $\mathrm{H}-8$ \\
\hline $9^{\prime}$ & $1.09(\mathrm{~s})$ & 29.59 & $\mathrm{H}-10^{\prime}$ & $1.01(\mathrm{~s})$ & 29.68 & $\mathrm{H}-10^{\prime}$ \\
\hline $10^{\prime}$ & $1.04(\mathrm{~s})$ & 26.34 & H-9' & $1.11(\mathrm{~s})$ & 25.82 & H-9' \\
\hline
\end{tabular}

${ }^{a}$ Carbon numbering used for compound $\mathbf{2}$ is maintained for $\mathbf{3}$ to facilitate a discussion.

${ }^{\mathrm{b}}$ Resonance multiplicities, coupling constants and coupled partners in parentheses: (s) singlet, (d) doublet), (t) triplet, (m) multiplet, (b) broad.

Isomers $\mathbf{3 a}$ and $\mathbf{3 b}$ could differ from each other on the position of the substituents on the $(i)$ carbon atom C-8: exo and endo isomers, and (ii) olefinic carbon atoms C-3' and C-8': $Z$ (cis) and $E$ (trans) isomers with respect to dimethyl-substituted carbon atom $\mathrm{C}-2^{\prime}$ and the bicyclooctane fragment. So, we considered four possible arrangements for compound 3, i.e., (Z)-endo, $(Z)$-exo, $(E)$ endo and $(E)$-exo, and three for compound 2, i.e., (ZZ), (EZ) and $(E E)$. The stereochemistry of products $\mathbf{2 a}, \mathbf{2} \mathbf{b}, \mathbf{3} \mathbf{a}$ and $\mathbf{3 b}$ can be elucidated by NOESY experiments.

The most relevant regions of the NOESY spectrum of mixture $\mathbf{3 a} / \mathbf{3 b}$ are expanded in Figures 4 and 5 and selected 
correlations are presented in Table 3. In both isomers, proton $\mathrm{H}-8^{\prime}$ gives NOE with $\mathrm{H}-9$ ' and $\mathrm{H}-10^{\prime}$ and no NOE with H-4' (Figura 4). Proton H-8 gives a strong correlation signal with $\mathrm{H}-4$ ' in $\mathbf{3 a}$ and $\mathbf{3} \mathbf{b}$ showing their spatial proximity in both isomers, whereas no NOE correlation is observed between H-8 and methyl protons H-9' and H-10' (Figura 5). This clearly indicates the $E$-configuration for both isomers as shown in Figure 3. For Z-configuration, opposite NOE correlation signals could be expected. This

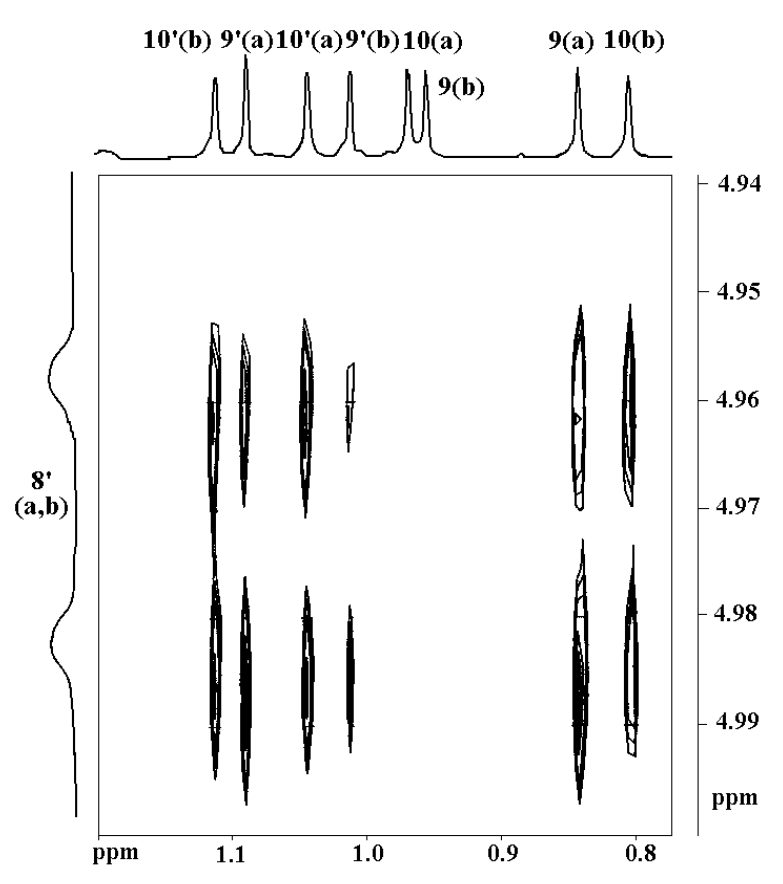

Figure 4. Selected region of the NOESY spectrum of $\mathbf{3 a} / \mathbf{3 b}$. is a sufficient proof to reject the (Z)-endo and (Z)-exo structures.

The further analysis of NOESY spectra allowed us to distinguish endo and exo isomers of ketone 3. In 3a, proton H-8 gives a correlation signal with the protons of the axial methyl group (H-10) and no correlation with the protons of the equatorial one (H-9), whereas in $\mathbf{3} \mathbf{b}$ the effects are opposite: H-8 gives NOE to H-9 and no NOE to H-10 (Figure 5). Based on these observations, we have attributed

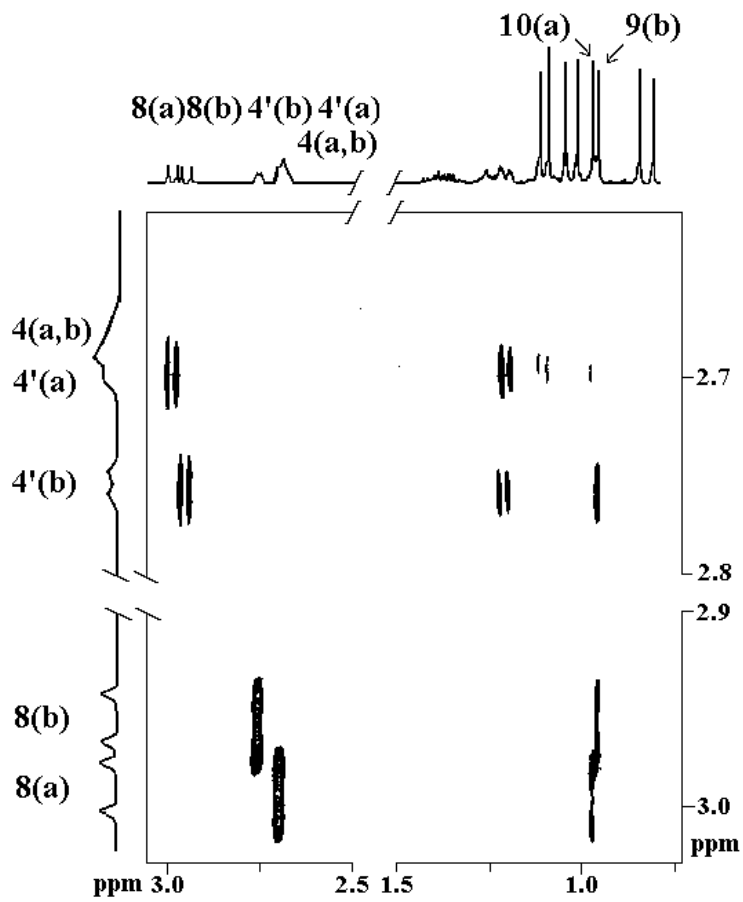

Figure 5. Selected regions of the NOESY spectrum of $\mathbf{3 a} / \mathbf{3 b}$.

Table 3. 2D ${ }^{1} \mathrm{H}$ NOESY NMR correlations in the compounds $\mathbf{2 a}, \mathbf{2 b}, \mathbf{3 a}$ and $\mathbf{3 b}$ (for the selected atoms)

\begin{tabular}{|c|c|c|}
\hline \multirow[t]{2}{*}{ NOESY correlation of $\mathrm{H}-$} & \multicolumn{2}{|c|}{ NOESY correlation with $\mathrm{H}-$} \\
\hline & isomer a & isomer $\mathbf{b}$ \\
\hline \multicolumn{3}{|c|}{ compound 2} \\
\hline $4,4^{\prime}$ & 8, 8'; 5ax, 5'ax; 5eq, 5'eq; 7a, 7'a; 7b, 7'b & 8, 8'; 5ax, 5'ax; 5eq, 5'eq; 7a, 7'a; 7b, 7'b \\
\hline $8,8^{\prime}$ & $4,4^{\prime} ; 9,9^{\prime} ; 10,10^{\prime}$ & $4,4^{\prime} ; 9,9^{\prime} ; 10,10^{\prime}$ \\
\hline $9,9^{\prime}$ & $1,1^{\prime} ; 8,8$ '; 7b, 7'b & $1,1^{\prime} ; 8,8$ '; 7b, 7'b \\
\hline $10,10^{\prime}$ & $1,1^{\prime} ; 8,8$ '; 6ax, 6'ax & $1,1^{\prime} ; 8,8$ '; 6ax, 6'ax \\
\hline \multicolumn{3}{|c|}{ compound $\mathbf{3}$} \\
\hline 8 & $4^{\prime}, 8^{\prime}, 10$ & $4^{\prime}, 8$,, 9 \\
\hline $4^{\prime}$ & $8,7^{\prime} \mathrm{a}$ & $8,9,7$ 'a \\
\hline $8^{\prime}$ & $8,9,9^{\prime}, 10^{\prime}$ & $8,9^{\prime}, 10,10^{\prime}$ \\
\hline 9 & $1,8^{\prime}, 7 \mathrm{~b}$ & 1,8 \\
\hline 10 & 1,8 & $1,8,7 \mathrm{~b}$ \\
\hline $9^{\prime}$ & $7 ' \mathrm{~b}, 8^{\prime}$ & $7 ' b, 8^{\prime}$ \\
\hline $10^{\prime}$ & $8^{\prime}$ & $7 ' \mathrm{~b}, 8^{\prime}$ \\
\hline
\end{tabular}


exo configuration for isomer $\mathbf{3 a}$ (shorter GC retention time) and endo for isomer $\mathbf{3 b}$. The following additional evidence confirms this assignment. The NOESY spectra show a strong correlation signal between olefinic proton $\mathrm{H}-8$ ' in 3a and the protons of the equatorial methyl group (H-9) but not the axial one ( $\mathrm{H}-10)$. On the other hand, in $\mathbf{3 b}$ a correlation is observed between $\mathrm{H}-8^{\prime}$ and $\mathrm{H}-10$ but not between H-8' and H-9 (Figure 4). Molecular modeling of 3 shows that olefinic proton $\mathrm{H}-8$ ' is spatially proximate to only one of the methyl groups of the bicyclooctane system: the equatorial (H-9) in the exo isomer and the axial (H-10) in the endo isomer. This proximity has been clearly revealed in NOESY spectra.

It is important to note the significant shielding observed for the resonances of the protons as well as the carbon atoms of the equatorial methyl group (C-9) in exo isomer 3a (0.84 ppm and 23.13 ppm for $\mathrm{H}-9$ and C-9 vs. $0.96 \mathrm{ppm}$ and $27.33 \mathrm{ppm}$ for $\mathrm{H}-10$ and $\mathrm{C}-10)$, and of the axial methyl group (C-10) in endo isomer $\mathbf{3 b}(0.95 \mathrm{ppm}$ and 26.15 ppm for $\mathrm{H}-9$ and C-9 vs. 0.80 ppm and 22.85 ppm for H-10 and C-10) (Table 2, Figure 4). The proximity of the bulk bicyclooctane group and the steric hindrance lead to a higher electron density on the equatorial methyl group in $\mathbf{3 a}$ and axial one in $\mathbf{3 b}$ resulting in these shielding effects. In addition to the anisotropic effect of the double bond, the steric interactions between atoms of the more hindered endo isomer should be more important so that most signals in the spectra of this isomer expectedly appear more shielded compared to those of the exo isomer (Table 2).

Thus, the two detected isomers of ketone 3 are the $(E)$ exo (3a) and (E)-endo (3b) forms (Figura 3 ).

The stereochemistry of diene $\mathbf{2}$ was also studied. We observed the formation of two predominant isomers, which could be $(Z, Z),(E, E)$, or $(Z, E)$-forms. Corresponding carbon and hydrogen atoms of both ring systems in each isomer show the same resonances in ${ }^{1} \mathrm{H}$ and ${ }^{13} \mathrm{C}$ NMR spectra, while most of the ${ }^{13} \mathrm{C}$ signals and some ${ }^{1} \mathrm{H}$ signals (vinyl and methyl protons) for two isomers are slightly different. ${ }^{13} \mathrm{C}$ NMR spectroscopy is a particularly valuable tool for the configurational assignment of trisubstituted alkenes $\left(\mathrm{RR}^{1} \mathrm{C}=\mathrm{CHR}^{2}\right)$. The principle involved is that the carbon nucleus cis to the $\mathrm{R}^{2}$ group will be shielded (5-7 ppm), through a " $\gamma$ compression effect", relative to the same carbon nucleus positioned cis to hydrogen. ${ }^{8}$ Resonances for carbons C-2 and C-2' as well as C-4 and C-4' attached to olefinic carbons $\mathrm{C}-3$ and $\mathrm{C}-3$ ', respectively, are very close for both isomers (cf. 42.42 ppm for C-2 and C-2' in 2a vs. 42.36 ppm in $\mathbf{2 b}$; and 41.51 ppm for C-4 and C-4' in both isomers) (Table 1). Therefore, all double bonds in two isomers have the same configuration and both compounds $\mathbf{2} \mathbf{a}$ and $\mathbf{2 b}$ should be either $(E, E)$ or $(Z, Z)$-forms.
Unfortunately, the results of NOESY experiments can not provide the necessary information to distinguish $(Z, Z)$ and $(E, E)$-forms, since, as mentioned above, the corresponding protons of both ring systems in each isomer of $\mathbf{2}$ show the same resonances. Stereochemistry of $\mathbf{2} \mathbf{a}$ and $\mathbf{2} \mathbf{b}$ was clarified by the comparative analysis of the ${ }^{13} \mathrm{C}$ NMR spectra of $\mathbf{2 a}$ / $\mathbf{2 b}$ and $\mathbf{3 a} / \mathbf{3 b}$. The chemical shifts of the carbon signals in the intact isocamphane systems of $\mathbf{3} \mathbf{a}$ and $\mathbf{3 b}$ are very close to those of $\mathbf{2} \mathbf{a}$ and $\mathbf{2} \mathbf{b}$. In particular, the chemical shifts of carbons C-2' and C-4' attached to olefinic carbon C-3' do not deviate more than 0.4 ppm (cf. 42.42/42.36 ppm for C$2^{\prime}$ in $\mathbf{2 a / 2 b}$ vs. $42.08 / 42.00 \mathrm{ppm}$ in $\mathbf{3 a / 3 b}$; and $41.51 \mathrm{ppm}$ for C-4' in $\mathbf{2 a / 2} \mathbf{b}$ vs. $41.35 / 41.39$ ppm in $\mathbf{3 a} / \mathbf{3 b}$ ) (Tables 1 and 2). This clearly shows that trisubstituted double bonds in all four compounds have the same configuration. Considering that for both $\mathbf{3 a}$ and $\mathbf{3 b}$ the NOESY study unambiguously proved the $(E)$-configuration, it is reasonable to propose $(E, E)$-configuration for both original isomers $\mathbf{2 a}$ and $\mathbf{2 b}$. This conclusion is also supported by mechanistic considerations: at the oxidation of diene 2 into ketone $\mathbf{3}$, the configuration of the intact double bond most likely remains unchanged, while the other undergoes palladation followed by the expansion of the isocamphane skeleton.

The further analysis of the NMR data helped us to elucidate some structural peculiarities of 2 . Conjugated dienes would be expected to adopt conformations in which double bonds are coplanar, so as to permit effective orbital overlap and electron delocalization. The two alternative planar conformations are referred to as s-cis and s-trans, with the latter being usually more stable. ${ }^{9}$ The analysis of molecular model structures shows that s-cis conformation for diene $\mathbf{2}$ is extremely unfavorable due to a steric hindrance of two bulky bicyclic fragments. A simulation of this structure, performed with the Chem3D program, shows that in a lowest-energy form the conjugated double bonds are not coplanar. Such a conformation is referred to as $s k e w^{9}$ in which the repulsion between the two isocamphane substituents is relieved. This hypothesis has been clearly proved by ${ }^{1} \mathrm{H}$ NMR spectroscopy. For both isomers $\mathbf{2} \mathbf{a}$ and $\mathbf{2 b}$, vinyl protons $\mathrm{H}-8$ and $\mathrm{H}-\mathbf{8}^{\prime}$ appear as singlets at 5.73 and $5.71 \mathrm{ppm}$, respectively, showing that there is no vicinal coupling between them. So, in the preferred conformations of both isomers two adjacent $\mathrm{C}-\mathrm{H}$ bonds are orthogonal $\left({ }^{3} J_{\mathrm{HH}} \cong 0\right.$ ) and conjugated double bonds are not coplanar. In Figure 2 the Newman projections along the C-8 - C-8' bond for two possible skew conformations of $\mathbf{2}$ resulting from right- or left-hand rotations about the $\mathrm{C}-8-\mathrm{C}-8$ ' bond are presented. Thus, compounds $\mathbf{2} \mathbf{a}$ and $\mathbf{2} \mathbf{b}$ formed by the oxidative coupling of the racemic camphene seem to be meso and $d l$ 
stereoisomers of the dimeric $(E E)$-diene existing preferentially in skew conformations (Figure 2).

\section{Conclusions}

The geometry of compounds $\mathbf{2}$ and $\mathbf{3}$ can now be discussed from a mechanistic point of view. The palladium catalyzed oxidative coupling of camphene seems to occur via the formation of the $\pi$-olefin palladium complex followed by the insertion of the coordinated camphene into the Pd-O bond resulting in a $\sigma$-organopalladium $\mathrm{C}_{10^{-}}$ intermediate. The later then reacts with another molecule of camphene, which inserts into the Pd-C bond in an antiMarkovnikov fashion, giving a $\mathrm{C}_{20}$-intermediate which contains the following fragment: $\left[>\mathrm{C}(\mathrm{X})-\mathrm{CH}_{2}-\mathrm{CH}_{2}-\mathrm{C}(\mathrm{Pd})<\right]$ $\left(\mathrm{X}=\mathrm{NO}_{3}{ }^{-}\right.$or $\left.\mathrm{OAc}^{-}\right)$. The stereochemistry of the final diene 2 $[>\mathrm{C}=\mathrm{CH}-\mathrm{CH}=\mathrm{C}<]$ is determined in the step of the decomposition of this palladium alkyl $\mathrm{C}_{20}$-intermediate via a $\beta$-hydrogen abstraction. Usually either cis- or the transalkene can be formed in such a step. However, for camphene derivative, both the PdH and HX eliminations are highly stereoselective, probably due to the large steric hindrance of two bulky isocamphane systems, and result mainly in $(E, E)$-isomer of diene 2. On the other hand, the further oxidation of diene seems to involve a palladation step, i.e., a nucleophilic attack on the face of the C-C double bond $\pi$ coordinated to palladium, followed by the heterolysis of the palladium-C- 8 bond and the rearrangement of the resulting carbonium ion with a cleavage of the C-2-C-3 bond and the formation of a new C-2-C-8 bond. Stereochemistry of final ketone $\mathbf{3}$ at C-8 is determined in the carbonium ion rearrangement step, which is not expected to be stereoselective. An alternative mechanism of the oxidative rearrangement of $\mathbf{2}$ via a $\pi$-allyl palladium complex and further C-2-C-3 bond cleavage does not appear also to be stereoselective. Consequently, the two isomers of ketone 3, i.e., (E)-exo (3a) and (E)-endo (3b) are formed in approximately equal amounts.

\section{Acknowledgments}

Financial support from $\mathrm{CNPq}$ (Conselho Nacional de Desenvolvimento Científico e Tecnológico) and FAPEMIG (Fundação de Amparo à Pesquisa do Estado de Minas
Gerais) is gratefully acknowledged. The authors wish to thank Prof. D. Piló-Veloso (Universidade Federal de Minas Gerais) and Prof. O. W. Howarth (Centre for NMR, University of Warwick, UK) for valuable discussions and Ms. Ivana Silva Lula for technical assistance in NMR experiements.

\section{References}

1. Erman, W. E.; Chemistry of the Monoterpenes. An Encyclopedic Handbook, Marcel Dekker: New York, 1985.

2. Chalk, A. J. In Catalysis of Organic Reactions; Rylander, P. N.; Greenfield H.; Augustine, R. L., eds.; Marcel Dekker: New York, vol. 22, 1988, p. 43.

3. Gusevskaya, E. V.; dos Santos, E. N.; Augusti, R.; Dias, A. O.; Robles-Dutenhefner, P. A.; Foca, C. M.; Barros, H. J. V.; Stud. Surf. Sci. Catal. 2000, 130, 563; Gusevskaya, E.; Gonçalves, J. A.; J. Mol. Catal. 1997, 121 131; Gusevskaya, E.; RoblesDutenhefner, P. A.; Ferreira, V. M. S.; Appl. Catal. 1998, 174, 177; Dias, A. O.; Augusti, R.; dos Santos, E. N.; Gusevskaya, E. V.; Tetrahedron Lett. 1997, 38, 41; Gusevskaya, E. V.; dos Santos, E. N.; Augusti, R.; Dias, A. O.; Foca, C. M.; J. Mol. Catal. 2000, 152, 15; da Rocha, L. L.; Dias, A. O.; Augusti, R.; dos Santos, E. N.; Gusevskaya, E.; J. Mol. Catal. 1998, 132, 213.

4. Andrews, M. A.; Chang, T. C.-T.; Cheng, C.-W. F.; Kelly, K. P.; Organometallics 1984, 3, 1777; Kiers, N. H.; Feringa, B. L.; Tetrahedron Lett. 1992, 33, 2403; Wenzel, T. T.; J. Chem. Soc., Chem. Commun. 1989, 932; Beck, I. E.; Gusevskaya, E. V.; Stepanov, A. G.; Likholobov, V. A.; J. Mol. Catal. 1992, $73,115$.

5. Mehta G., Indian J. Chem. 1973, 11, 843.

6. Gordon, A. J; Ford, R. A.; The Chemist's Companion, Wiley: New York, 1972.

7. Roeges, N. P. G.; A Guide to the Complete Interpretation of Infrared Spectra of Organic Structures, Wiley: Wiltshire, 1995.

8. Eliel, E. L.; Wilen, S. H.; Mander, L. N.; Stereochemistry of Organic Compounds, Wiley: New York, 1994.

9. Carey, F. A.; Sundberg, R. J.; Advanced Organic Chemistry, Plenium Press: New York, Part A., 1990.

Received: March 14, 2002 Published on the web: January 31, 2003 